\title{
Future storm surge impacts on insurable losses for the North Sea region
}

\author{
L. Gaslikova ${ }^{1,2, *}$, A. Schwerzmann ${ }^{3}$, C. C. Raible ${ }^{1,2}$, and T. F. Stocker ${ }^{1,2}$ \\ ${ }^{1}$ Climate and Environmental Physics, Physics Institute, University of Bern, Sidlerstraße 5, 3012 Bern, Switzerland \\ ${ }^{2}$ Oeschger Centre for Climate Change Research, Zähringerstraße 25, 3012 Bern, Switzerland \\ ${ }^{3}$ Swiss Reinsurance Company, Zurich, Switzerland \\ *now at: Helmholtz-Zentrum Geesthacht, Centre for Materials \& Coastal Research, Germany
}

Received: 17 June 2010 - Revised: 17 February 2011 - Accepted: 25 February 2011 - Published: 29 April 2011

\begin{abstract}
The influence of climate change on storm surges including increased mean sea level change and the associated insurable losses are assessed for the North Sea basin. In doing so, the newly developed approach couples a dynamical storm surge model with a loss model. The key element of the approach is the generation of a probabilistic storm surge event set. Together with parametrizations of the inland propagation and the coastal protection failure probability this enables the estimation of annual expected losses. The sensitivity to the parametrizations is rather weak except when the assumption of high level of increased mean sea level change is made. Applying this approach to future scenarios shows a substantial increase of insurable losses with respect to the present day. Superimposing different mean sea level changes shows a nonlinear behavior at the country level, as the future storm surge changes are higher for Germany and Denmark. Thus, the study exhibits the necessity to assess the socio-economic impacts of coastal floods by combining the expected sea level rise with storm surge projections.
\end{abstract}

\section{Introduction}

Coastal areas are historically highly populated and extensively utilized. In Europe, about 200 million people live in coastal zones and the population density of the North Sea coasts has currently reached 250 inhabitants per $\mathrm{km}^{2}$ (Eurostat Regio database, 2009). It is a long-term necessity to protect near-shore and low-lying areas from sea impacts. In spite of considerable protection and planning efforts, coastal flood events caused by storms take place and lead to casualties

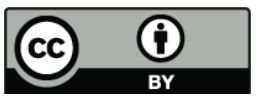

Correspondence to: L. Gaslikova (lidia.gaslikova@hzg.de) and property damage (e.g., the North Sea flood of 1 February 1953, the Hamburg flood of 17 February 1962, etc.). In the face of future climate change, whose consequences include mean a sea level rise and a possible intensification of storms, concern rises about increasing frequency and intensity of coastal flood events (Bindoff et al., 2007).

The part of the total sea level mainly driven by meteorological conditions is the storm surge. It is defined as the difference between the total water level and tide. High storm surge levels are associated with short-term (several hours) elevated water events, which can lead to flooding, especially when coinciding with high tide. A specific feature of such mid-latitude storms is an extensive area of impact of several hundred kilometers (Gönnert et al., 2001).

Modelling studies have demonstrated the ability of the surge models to represent the storm surge residuals adequately (Flather et al., 1998; Weisse and Pluess, 2006). Based on multi-decadal model simulations, both of these studies stated that storm surge extremes showed high interannual and spatial variability during past decades. However, conclusions about the trends and possible intensification in the past storm surge extremes are ambiguous so far. The increase of the upper percentiles of the surge level for the North Sea was detected during the period of 1958-2000 based on measurements as well as on the dynamical simulations with the highest trends in the German bight (Weisse and Pluess, 2006). The authors pointed out that the rate of change varies significantly depending on the analyzed period. They found that the number and intensity of surge extremes has remained nearly constant during the last years of the 20th century. These results are in line with the findings of Alexandersson et al. (2000) and Weisse et al. (2005) for the storminess in the northeastern Atlantic. Alexandersson et al. (1998) and Matulla et al. (2008) also found that the present day storminess

Published by Copernicus Publications on behalf of the European Geosciences Union. 
in northwestern Europe has returned to the average conditions of the 20th century after the intensification of 1960th1990th. One reason for this is that the atmospheric forcing, i.e., the midlatitude storms, shows strong variations and even contradicting trends when analyzing different reanalysis data sets (Raible et al., 2008).

For the future climate, recent studies have suggested intensification of wind storms in northwestern Europe for future development scenarios (Ulbrich et al., 2009). In particular, an increase of the upper wind speed percentiles up to $10 \%$ and a decrease of the mean winter sea level pressure by $5 \mathrm{hPa}$ were detected for the end of the 21st century (Beniston et al., 2007). Rockel and Woth (2007) also confirmed the increase of extreme near-surface wind speeds based on the results of several regional atmospheric models. An intensification of westerly wind extremes is likely to cause increased storm surge extremes for the future climate. Thus, future projections for storm surge activity show intensification of surge extremes with more pronounced increase of surge levels for the south- eastern North Sea (Lowe et al., 2001; Woth, 2005a; Debernard and Røed, 2008). In general, this effect is robust throughout various regional atmospheric models as well as storm surge models. However, Lowe and Gregory (2005) pointed out that different sources of uncertainty are responsible for rather variable local changes in storm surge extremes when different studies are compared. Such sources can be atmospheric conditions from different atmospheric models, storm surge model setups, global and regional sea level rise estimates and future development scenarios. For example, the intensification of storm surges for the south- eastern coast of England found by Lowe et al. (2001) could be only partially confirmed by Debernard and Røed (2008) and was not detected by Woth (2005a).

Given these changes, the quantification of associated risks is of great interest to the insurance industry. During past decades the insurance losses caused by weather-related hazards (e.g., wind storms, floods, droughts, hail) have increased or increased significantly (Schwierz et al., 2009). Along with an increased population, redistribution of insured property and increased insurance penetration, the changes in natural hazards are the reason for such a tendency (Swiss Re, 2003). The key question is how the extreme conditions will develop in the future and what changes in the risks and losses can be expected for different future projections.

Thus, this study pursues two goals. The first is to construct a storm surge loss model, i.e., a combination of a statistical insurance loss model and a hydrodynamic storm surge model. This coupling allows realistic storm surge situations and corresponding occurrence probabilities to be considered, from which the loss potential for the historical climate as well as for future climate scenarios can be estimated. The second objective is to estimate the impact of climate change consequences on the insurance loss burden for the North Sea basin. The study focuses on the changes in storm surge climatology and sea level rise and considers coastal flooding as

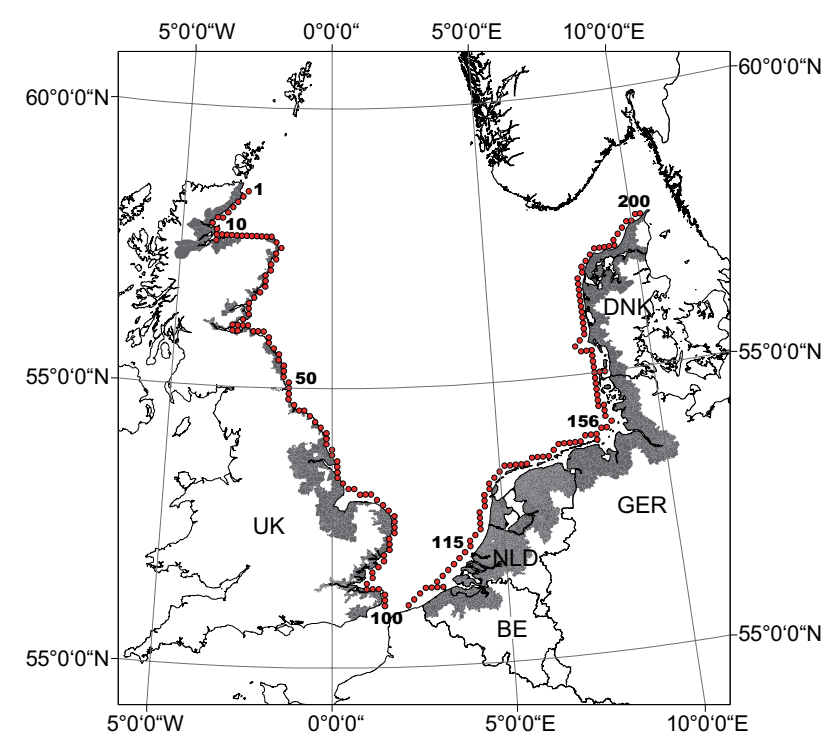

Fig. 1. Model area for storm surge models. Points 1-200 follow the $10 \mathrm{~m}$ depth contour line. Shading indicates postal code areas with land elevation $<10 \mathrm{~m}$.

the only peril and insurable property as the only hazard recipient, leaving effects such as coastal erosion, wetland loss, and salt water intrusion beyond the scope of this work. To get a first impression of the extension of the coastal areas at risk, a rough estimate of potentially exposed areas is obtained by assessing land elevations from the Digital Terrain Model. Figure 1 shows the areas aggregated by postal code units and potentially prone to flooding in the absence of coastal protection, i.e. with the average land elevation less than $10 \mathrm{~m}$ and located closer than $50 \mathrm{~km}$ to the present day coastline. Thus, the damage of these areas can be considered as the worst case scenario of a storm surge impact.

The paper is organized as follows: in Sect. 2 the storm surge data sets are described, Sect. 3 explains the methodology of the data processing and Sect. 4 is dedicated to the loss model as a whole. Results are presented in Sect. 5, limitations and conclusions are discussed in Sect. 6.

\section{Storm surge data and sea level rise scenarios}

To develop the methodology and to test the loss model, the storm surge data set of Weisse and Pluess (2006) was used as a hindcast or reference historical data set. It provided simulated sea levels for the North Sea region covering the period 1958-2002 at an hourly resolution. The data set was generated with the TELEMAC2D hydrodynamic model (Hervouet and Haren, 1996), which utilized an unstructured mesh varying from $75 \mathrm{~m}$ to $27 \mathrm{~km}$. Atmospheric forcing was obtained by dynamically downscaling the NCEP/NCAR reanalysis (Kistler et al., 2001) to a $50 \mathrm{~km}$ resolution with the 
SN-REMO regional atmospheric model (Feser et al., 2001). External surge estimated from the tide-gauge measurements at Aberdeen and the tidal cycle were prescribed on lateral boundaries. For our study, water level data were interpolated to a $10 \times 10 \mathrm{~km}$ regular grid in order to be consistent with the scenario data (described below). Storm surge residuals were estimated by removing the tidal cycle from the water level time series. Grid cells along the $10 \mathrm{~m}$ depth contour line were used for further analysis (Fig. 1).

Storm surge scenarios (Woth, 2005a; Christensen et al., 2002) were used to reflect potential changes in storm surge statistics due to future climate change. A hierarchy of numerical models was applied to estimate the impact of global greenhouse gas emissions on regional surge elevations. Present day conditions (1961-1990) (control simulation) and future conditions (2071-2100) according to IPCC SRES A2 and B2 scenarios were simulated with a GCM (ECHAM/OPYC4, Roeckner et al., 1999). Then, atmospheric conditions were dynamically downscaled to the resolution of $50 \times 50 \mathrm{~km}$ for the European region with the RCAO regional circulation model (Döscher et al., 2002). The resulting sea level pressure and $10 \mathrm{~m}$ wind were used as forcing for the tide-surge model TRIMGEO (Casulli and Cattani, 1994). The model domain comprised the northwestern European continental shelf and the North Sea. On the lateral boundaries only the tidal cycle was prescribed, no external surge was considered. Water levels were stored every $30 \mathrm{~min}$ on the resolution $6^{\prime} \times 10^{\prime}$ (or approximately $10 \times 10 \mathrm{~km}$ ). The TRIMGEO model has been validated for the historical simulation against tidal gauge measurements. It was found that the model reasonably reproduced regional water levels (Aspelien and Weisse, 2005) as well as storm surge statistics (Woth et al., 2006) with some deficiencies which will be addressed in Sect. 3.2.

In addition, a "tide only" simulation, produced without atmospheric forcing, was used to extract storm surge residuals. Storm surge heights were analyzed on the original $10 \times 10 \mathrm{~km}$ resolution for the locations following the $10 \mathrm{~m}$ depth contour line along the North Sea coasts (see Fig. 1).

Apart from the possible storm intensification in the North Sea region, sea level rise (SLR) is a widely expected consequence of the future climate. SLR not only affects the coastline itself, it can also enhance the impact of a storm surge on the coast. When the storm surge height is superimposed on higher water levels, it causes more damage as the total water elevation is higher. The return period of a certain flood elevation decreases as the mean sea level increases. This means that floods occur more frequently even if the storm surge climatology remains unchanged. According to the last IPCC estimates (Bindoff et al., 2007), the projected SLR varies from 20 to $50 \mathrm{~cm}$ for the end of $21 \mathrm{st}$ century, depending on the specific scenario. An additional source of uncertainty which is not included in IPCC scenarios so far originates from ice sheet instabilities, of which the mechanisms are not completely understood and poorly quantified. The regional SLR scenarios currently available provide rather qualitative information and show a strong spatial variability among different members of the multi-model ensemble. Additional scenarios constructed with regional circulation and surge models are needed to reduce this uncertainty (Bindoff et al., 2007).

For our study two SLR scenarios were considered, namely a moderate $0.5 \mathrm{~m}$ and extreme $1 \mathrm{~m}$ sea level rise for the end of 21st century. These increments were linearly added to surge heights. Although surge formation can be altered by changed sea level, especially in the shallow near shore zones, it has been shown that on a regional scale (i.e. $5-50 \mathrm{~km}$ ), the non-linear effect of sea level and storm surge interaction is negligible (e.g., Lowe et al., 2001). Note that local vertical land movements associated with post-glacial rebound or land subsidence were not taken into account.

\section{Building the storm surge event set}

In this section the general concepts of the event set and hazard set are introduced. Each event is a spatial distribution of one or several parameters which are relevant for hazard assessments. An event is associated with a phenomenon (e.g., a storm) strong enough to cause damage and having a stochastic nature. In the case of coastal flooding, the most important parameter for assessment of damage is the water level. In our model a single event represents simultaneous storm surge heights along the North Sea coastline. Events associated with different time steps build an event set. For each event, the probability of occurrence and intensity are estimated. The hazard set is a combination of an event set and additional non-stochastic effects such as SLR or tide at points of interest. A point can represent a geographical location, a single building or some larger objects like a postal-code area or a town. Losses can be estimated for each hazard event (i.e., water levels inland) and combined in economically relevant measures (for details see Sect. 4).

Several approaches are commonly used to estimate economic and, in particular, insurance losses associated with hazards. One is the "deterministic" approach, where the economic impact is assessed for simple cases, often represented by single historical events. This allows estimating losses associated with certain realistic extreme events, in case there are enough historical data available. However, this approach provides limited information concerning the probability of occurrence of such events in the future or annual expected losses for the portfolio.

Another approach uses data statistics such as percentiles or return values estimated from historical events or simulated continuous time series. This is often utilized in economic impact studies (Nicholls, 2004). The method is appropriate when the upper limits or the "worst case" of an impact is of interest, but it fails to assess annual expected losses. 


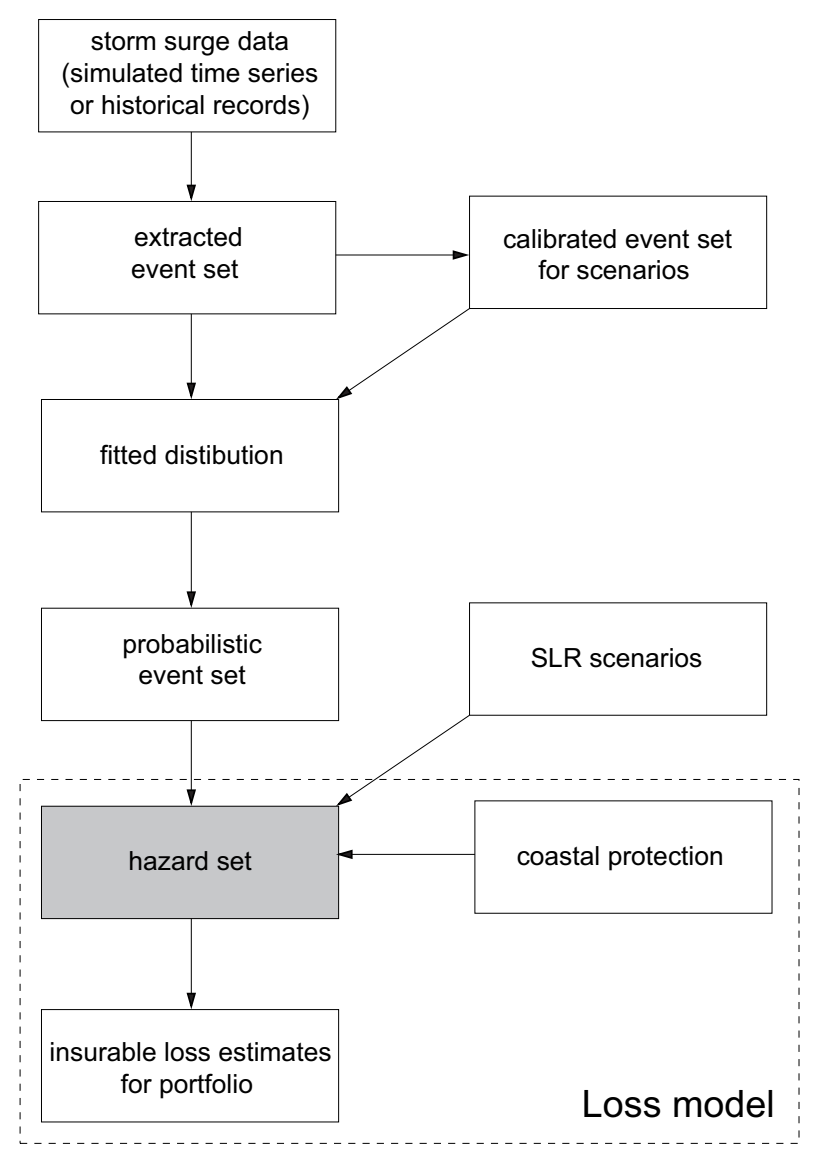

Fig. 2. Flowchart of the construction of a hazard set.

In this study we use a combination of deterministic and probabilistic strategies. Losses are estimated for each event separately, as in the deterministic case. However, not only historical events are considered, but also those which could potentially occur, that means they are as probable from the physical point of view as recorded events. This allows us to consider events which are too rare or just have not occurred within the modeled/measured period of time.

The key stages and processes of the method are illustrated in the flowchart of Fig. 2. It starts with the construction of the event set by identifying events from the historical (and later the scenario) data set. Then based on these events, a certain distribution is fitted. Finally, the original event set is expanded by adding events sharing the same distribution to create a probabilistic event set. In the remaining part of this chapter only event set issues are discussed, i.e. offshore storm surge heights are in focus.

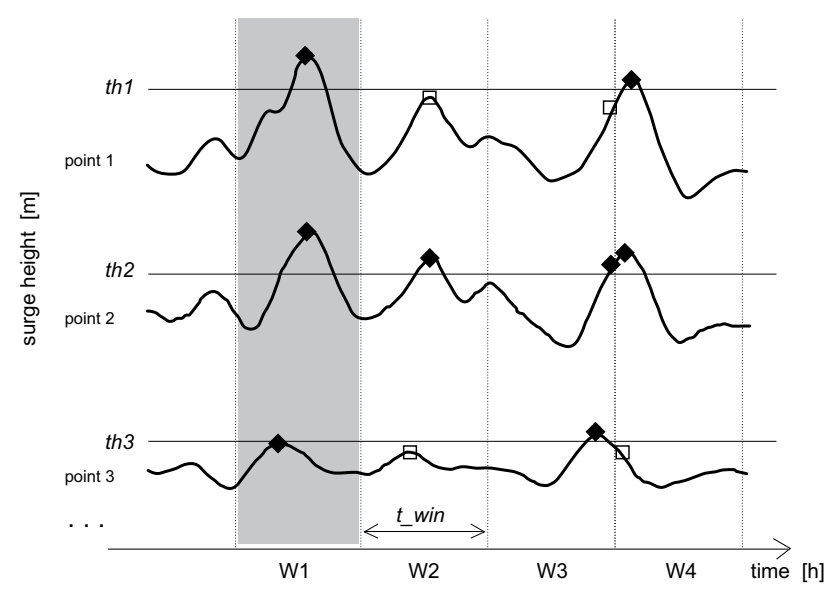

Fig. 3. Schematic description of the event definition. A sequence of adjacent time windows W1, W2, W3, W4 with duration t_win is defined. Diamonds represent local maxima exceeding the thresholds th1, th2 and th3, squares - maxima not exceeding the thresholds for every time window. Only the shaded W1 time window for which $N$ (here 3) local maxima exceed the threshold yields an event.

\subsection{Defining the probabilistic event set}

A crucial issue is the definition of a single event and the way the event set is constructed.

The development of the following method is governed by several requirements to the resulting event set. First, each event should retain the spatial distribution of water levels for single storms, e.g., for an event which corresponds to a storm hitting only the German Bight (e.g., on 16 February 1962), water elevations for other regions remain low. A second prerequisite is the independence of events in the set. Third, a storm is considered as an event if the water level exceeds a certain threshold for several locations simultaneously, which guarantees that high water elevation was not a result of local effects. Additionally, the event set should contain a sufficient number of events to apply statistics and to fit events to the same distribution family for all locations.

To fulfill the prerequisites, the approach entails splitting the time series into periods of equal duration and selecting maxima for each period and each location (Fig. 3). The time window of $120 \mathrm{~h}$ is selected to keep the spatial patterns of single storms for the entire area of interest. Storm surge propagation speed and track depend on the atmospheric circulation, but in most cases the surge progression is similar to the diurnal tide. Namely, it progresses counterclockwise from Scotland via the Netherlands to Denmark. Although extremely high water caused by a surge (higher than 99-percentile) can affect each particular site only for several hours (on average about $5 \mathrm{~h}$ for UK and 6-9 h for Germany), a single storm can influence different coastal areas of the region within 2-3 days (Gönnert et al., 2001). Thus the time 

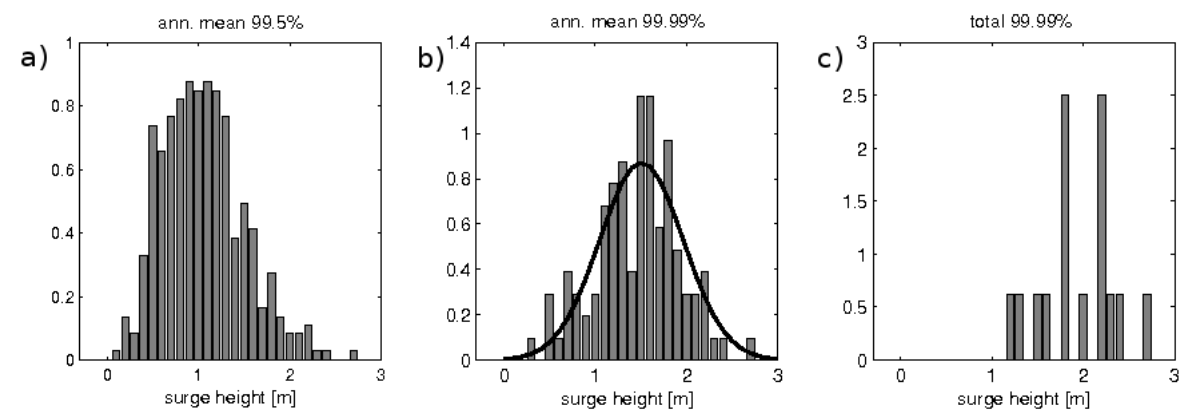

Fig. 4. Histograms for hindcast storm surge events at point 156 (location see Fig. 1) obtained with thresholds (a) annual mean $99.5 \%$, (b) annual mean $99.9 \%$, (c) total $99.99 \%$. Histograms are normalized to unit area. Solid line shows the probabiliry density of the fitted normal distribution.

window of $120 \mathrm{~h}$ guarantees the independence of events in the set.

Additionally, only the maxima which exceed a certain threshold are considered as local events (gray diamonds, Fig. 3). Time windows with exceedances of more than $N$ locations are included into the final event set (shaded time slots, Fig. 3). Here, $N=10$ is used to include storm events which simultaneously cause high water for at least $100 \mathrm{~km}$ of the coastline. Thresholds are estimated for each location separately based on the local storm surge statistics. They are chosen in a way to keep a balance between too high thresholds which result in only too few events to fit any distribution and too low values, when a part of events are too weak to generate flooding. The annual mean 99.99-percentile level is used as a threshold for the model. The obtained set of surge water levels can be approximated by a normal distribution. The normality tested for each location with a Chisquared test could not be rejected on the $95 \%$ significance level. Other thresholds were tested (Fig. 4), e.g., total 99.99percentile, which appeared to be too high. Extreme events exceeding these thresholds are too rare to provide statistically reasonable results. Moreover, mean annual percentiles are more robust and not very sensitive to singular very high events, which makes this value more suitable as a threshold than total percentiles. Lower values, such as the annual mean 99.5-percentile, allowed too many events with low water elevations to be included into the event set. The related distribution was skewed and the normality assumption had to be rejected.

The use of fixed time windows can cause a splitting of a single storm where both parts, which fall in different time windows, are high enough to be considered as events (e.g., Fig. 3, time windows W3 and W4 for point 2). The amount of such split events is about $10 \%$ of the total number of selected events. This rate holds for the particular combination of threshold and time window duration. The influence of these artificially repeating events on the final distribution has been tested (1) by shifting all time windows by half of the period (2) by selecting only the largest of every two events appeared due to the splitting for each location (e.g., in Fig. 3 for point 2 the value for $\mathrm{W} 3$ would be removed and the value for W4 would be kept). In both cases no significant changes were found for the resulting distribution shapes. For the test (1) frequency of the events remained unchanged as well. The changes in frequency of about 7\%-9\% found during the test (2) are not relevant for further method development and will be discussed in Sect. 5 .

To summarize, the method of event extraction has three parameters that are selected in order to fulfill the assumptions listed above: duration of time window $(120 \mathrm{~h})$, water level thresholds (annual mean 99.99-percentile), and number of surpasses (10). For each location the extracted event set is fitted to a normal distribution with its own parameters. Based on those and the spatial correlation of event sets from different locations, a set of random events is generated (probabilistic event set). Each component event reflects a potentially possible storm surge level distribution along the North Sea coastline. The total set of 20000 probabilistic events is further used to generate the hazard set.

\subsection{Calibration of scenario data}

The method described in the previous section was applied to storm surge hindcast and scenario data sets. Event sets were built for the hindcast representing the 1958-2002 period, for the control $(\mathrm{Ctl})$ data set interpreted as present day climate conditions, as well as for SRES emission A2 and B2 scenarios representing future climate. These are based on reanalysis products and model simulations described in Sect. 2. To compare the extreme intensities of the events originating from different event sets, the 90-percentiles were calculated for each location based on these event sets (Fig. 5). Both $\mathrm{Ctl}$ and A2 storm surge upper percentiles underestimate those from the hindcast. The difference between $\mathrm{Ctl}$ and hindcast is up to $50 \mathrm{~cm}$ for continental coasts; it increases along the 


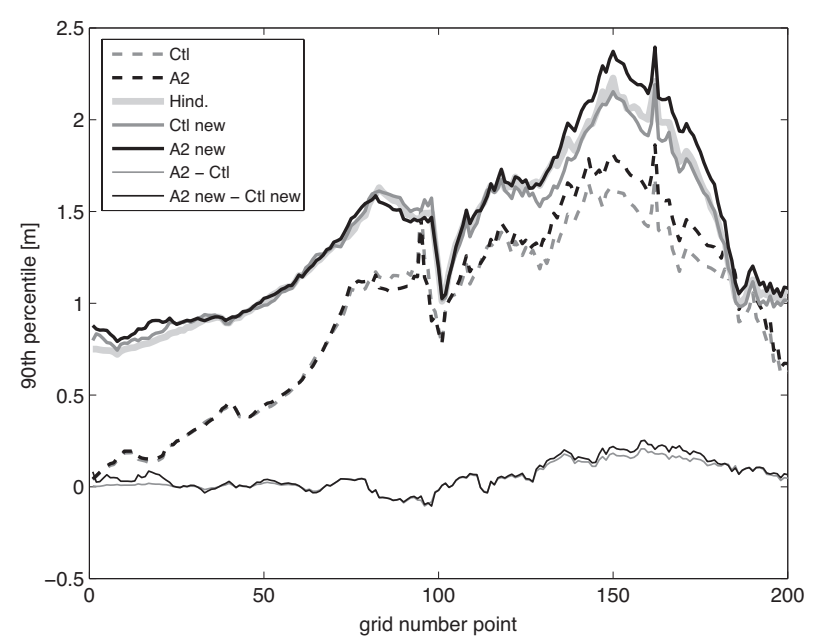

Fig. 5. 90-percentiles for hindcast and scenario storm surge event sets. Original and calibrated (new) event sets are considered. For grid point location see Fig. 1.

east coast of England and reaches $75 \mathrm{~cm}$ for the northeast coasts of Scotland.

This can be traced to two reasons. One was pointed out by Woth et al. (2006), namely, the absence of external surges in TRIMGEO simulations. For the hindcast, on the contrary, the external surges generated beyond the model area (in our case northwest from the British Islands) and entering the North Sea from the north, were considered by applying a data assimilation of measured water levels in $\mathrm{Ab}$ erdeen. This had a major impact on the UK coasts. Another reason is that extreme wind speeds (e.g., the 99 percentiles) are usually underestimated in control simulations (for various global and regional models) with respect to reanalysis (e.g., Flather et al., 1998). Consequently, storm surge extremes simulated with such atmospheric forcing are also underestimated (Lowe et al., 2001; Woth, 2005b).

Although underestimated surge extremes still give an impression of the range of future and present climate differences, the discrepancy with the hindcast can become crucial when the absolute values of storm surge heights are important. Thus, economic losses for coastal areas attributed to flooding strongly depend on the amount of inundating water and resulting water levels inland. This is driven mainly by water elevation in front of the coast. A significant underestimation of storm surge elevation can cause big uncertainties for estimated losses. To minimize this effect, storm surge event sets based on the scenarios are calibrated towards the hindcast event set. For that, the cumulative distribution function $(\mathrm{CDF})$ for each location from the $\mathrm{Ctl}$ event set is corrected by a linear transformation to fit the CDF from the hindcast (Fig. 6). A similar method was suggested by Raible et al. (2011). The same linear transformation coefficients are applied to the A2 and B2 event sets. The calibrated event
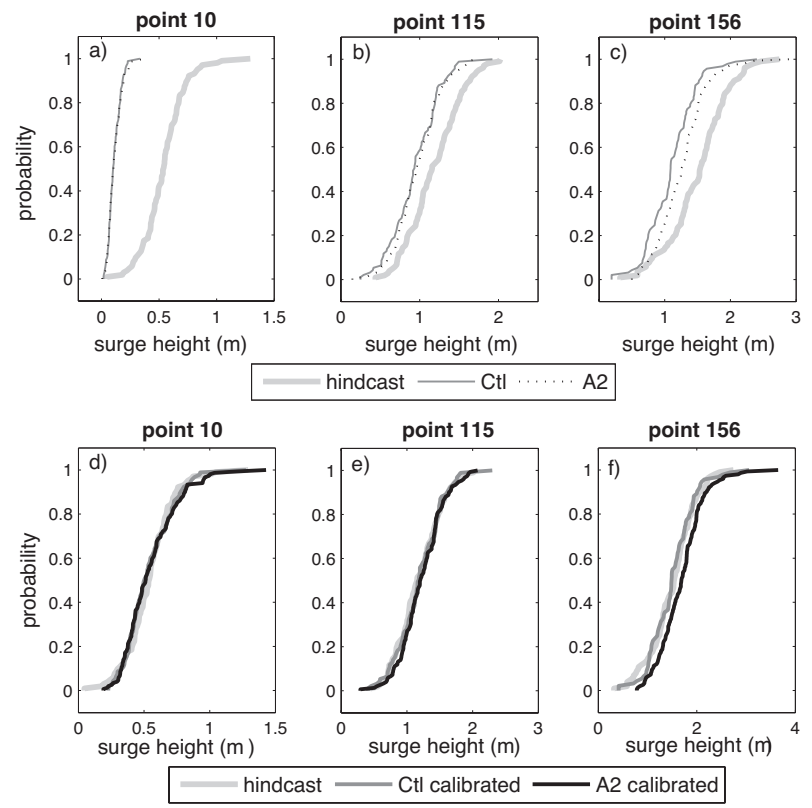

Fig. 6. Examples of three points 10, 115, 156 (location see Fig. 1) for the cumulative distributions of hindcast and scenario storm surge event sets: uncalibrated $(\mathbf{a}, \mathbf{b}$ and $\mathbf{c})$ and calibrated $(\mathbf{d}, \mathbf{e}$ and $\mathbf{f})$.

set for the control period agrees better with the hindcast, as illustrated by the 90th percentiles (Fig. 5). For future scenarios, absolute differences between calibrated A2 (B2) and $\mathrm{Ctl}$ event sets remain almost unchanged with respect to the ones found before calibration (Fig. 5). The changes associated with A2 scenario (so far only atmospherically driven changes, no SLR included) are about $20 \mathrm{~cm}$ for the German Bight, decreasing for the Netherlands and Denmark and becoming close to zero or slightly negative for the UK. For the more moderate B2 scenario, the maximum differences are about $15 \mathrm{~cm}$ (not shown).

\section{Loss model}

The frame for insurable loss estimations is provided by the loss model, an operational model used at Swiss Reinsurance Company Ltd (Swiss Re), in a modified form for storm surge applications. The model consists of four principal modules:

- Hazard - Where, how often, and with what intensity do events occur?

- Vulnerability - What is the extent of damage at a given event intensity?

- Value distribution - Where are the various types of insured objects located and how high is their value?

- Insurance conditions - What are the conditions of the insurance coverage (i.e. deductible)? 
Annual expected losses (AEL - estimated annual losses averaged over a long period of time) and loss frequency curves reflecting the loss magnitude for events of a certain frequency are the output variables of primary interest. The results are aggregated on a country basis, although the model itself works with a regular grid and postal code areas. The last three modules are directly linked to insurance conditions and implemented based on the Swiss Re expertise. In particular, the value distribution based on a subset of the insured market portfolio of wind exposure is used in this study. The subset includes all areas potentially prone to flooding. Due to the lack of consistent storm surge insurance conditions in the modelled area, (each country handles storm surge insurance coverage differently), this wind portfolio can be interpreted as a hypothetically insurable storm surge portfolio. The portfolio includes residential, commercial and industrial values. It considers both property damage and business interruption risks.

In this section we focus on the first module of the loss model, namely the hazard set generation. As described in Sect. 3, the hazard set is constructed based on the event set. In our case this comprises consideration of SLR and transformation of sea levels off-shore to the water levels inland. A large amount of considered events and a vast model area do not allow direct modeling of water propagation with a hydrodynamical model. Instead, a simplified approach used here considers two major processes: the water depth alteration due to inland propagation and the possible failure of coastal protection constructions.

\subsection{Inland penetration}

Flood extent and depth were estimated assuming no coastal protection, i.e., any positive water level in front of the coast causes water propagation inland. This provided the "worst case" with the maximum possible flood depths under the present/future climate conditions. The estimates were made for a regular grid and then aggregated to the postal code areas. Land elevation was represented by a digital terrain model (DTM) with $100 \mathrm{~m}$ resolution provided by Intermap Technologies Inc. Additionally, to reflect the limited amount of water available in case of flooding, we assumed the linear decrease of flood depths with the increasing distance from the flood source.

\subsection{Coastal protection failure probability}

The coastal protection facilities are introduced as it is crucial for a realistic flood damage assessment.

Historically, protection constructions were of local importance and were developed and designed with respect to local conditions. Thus, there are different specifications and criteria for protection constructions. Even if most of the characteristics are currently widely used, they may have similar but not identical definitions (see e.g. Jorissen et al., 2000). In
Table 1. Data sources for the coastal protection.

\begin{tabular}{|c|c|}
\hline Country & Authority or reference document \\
\hline Denmark & Ministry of Transport \\
\hline \multirow[t]{2}{*}{ Germany } & $\begin{array}{l}\text { Ministry of Agriculture, Environment and } \\
\text { Rural Areas the State of Schleswig-Holstein } \\
\text { (Generalplan Küstenschutz) }\end{array}$ \\
\hline & $\begin{array}{l}\text { Lower Saxony Water Management, Coastal } \\
\text { Defence and Nature Conservation Agency }\end{array}$ \\
\hline Netherlands & $\begin{array}{l}\text { Ministry of Transport, Public Works and } \\
\text { Water Management }\end{array}$ \\
\hline Belgium & $\begin{array}{l}\text { Agency for Maritime and Coastal Services, } \\
\text { Flanders }\end{array}$ \\
\hline UK & Environment Agency \\
\hline
\end{tabular}

Germany the crest level (CL) is given as a standard dam characteristic, but in two states (Schleswig-Holstein and Lower Saxony), the methods of CL estimation are different (Loffredo et al., 2007). Another characteristic is the safety standard of protection (SOP) in return periods of extreme water levels. For Germany, protection levels are prescribed which withstand no less than a 100-yr event. But considering safety margins, the safety is usually higher (although not officially estimated how much higher). In the Netherlands and Belgium, the SOP is prescribed on a national level, varying from 1250 to 10000 -yr return periods for the Netherlands and 1000-yr return periods for Belgium. In the United Kingdom there are no common regulations; local authorities specify protection safety levels and dam design. Indicative safety levels vary from 200-yr return periods up to 1000 -yr values for the London area. A similar situation prevails in Denmark, where protection levels of 200 to 1000 -yr return periods with higher levels for major towns are accepted. Dike overflow is usually considered as a prime failure mechanism, for which the standard of protection is estimated. Other dam failure mechanisms (e.g., uplifting, piping), which are not always explicitly considered in safety standards, change the total failure probability. This can happen in both directions, e.g., overestimation of actual safety state for some dams in the Netherlands (Floris project, 2005) or underestimation of safety, as in the case of Germany.

For the sake of the universality of the loss model and to obtain consistent results for the entire model area, a uniform way to consider the dam safety for all the countries was required. Two parameters, SOP and CL, were taken as a basis for failure probability estimations. For each country, dams were identified along the coastline and corresponding SOP and CL magnitudes were assigned, where available. The data were obtained from national authorities of corresponding countries (for details see Table 1) and adapted to the loss 
model structure. The length of the dam sections in the model varied from $100 \mathrm{~m}$ to $1 \mathrm{~km}$. The loading variable, i.e., the magnitude which influences the dam failure, is given by water level in front of the protection construction. The duration of the high water event and the influence of waves on the protection construction were not accounted for explicitly.

Two main failure mechanisms are implied, overflowing and breaching. We assumed overflowing happened when the water load was greater than the actual dam height (CL) and set the corresponding failure probability to $100 \%$. For breaching, an exponential shape of failure probability depending on the load is assumed as a generalization of experimental studies of dike and dune fragility due to different types of failure (Dawson and Hall, 2006). A water level equivalent of SOP (originally given as the return period) is obtained as a sum of the corresponding storm surge return values and maximum high tide for each off-shore point along the coast. For that annual maxima from the storm surge, hindcast data set were fitted by the Generalized Extreme Value distribution (Gumbel, 1958) for off-shore locations and return values corresponding to the return periods given by SOP were estimated. We defined five load categories with different failure probabilities $\left(p_{1}-p_{5}\right)$ based on SOP and CL (see Table 2). A similar shape of the failure probability distribution with respect to SOP was applied by Hall et al. (2003) for the UK coasts and adapted here to other countries. Additionally, the linear efficiency coefficient $\left(a_{\mathrm{c}}\right)$ which is unique for each country is applied to the failure probability distribution (for values see Table 3 ). It is based on the Swiss Re loss experince and reflects the differences in SOP and CL definitions among the countries and other country-specific features. The final failure probability curve is constructed as $a_{\mathrm{c}} \times p_{i}$. The sensitivity of the model results to the changes in the failure probability distribution as well as the efficiency parameters are discussed in Sect. 5.

\subsection{Loss model hazard set}

The finalized hazard set is constructed as a linear combination of storm surge event sets, described in Sect. 3 for the control simulation and future scenarios, SLR scenarios and four cases of tidal heights. The high surge coincidence with a certain tidal phase is practically unpredictable. To cover various combinations and to keep the occurrence frequency unchanged, the event set was expanded by adding four tide cases: mean high, low tides and two mean water levels. By these means, the probability of occurence of each of these events is the same, namely 0.25 , because within one tidal cycle the mean water level occurs 2 times and high and low water occur once.
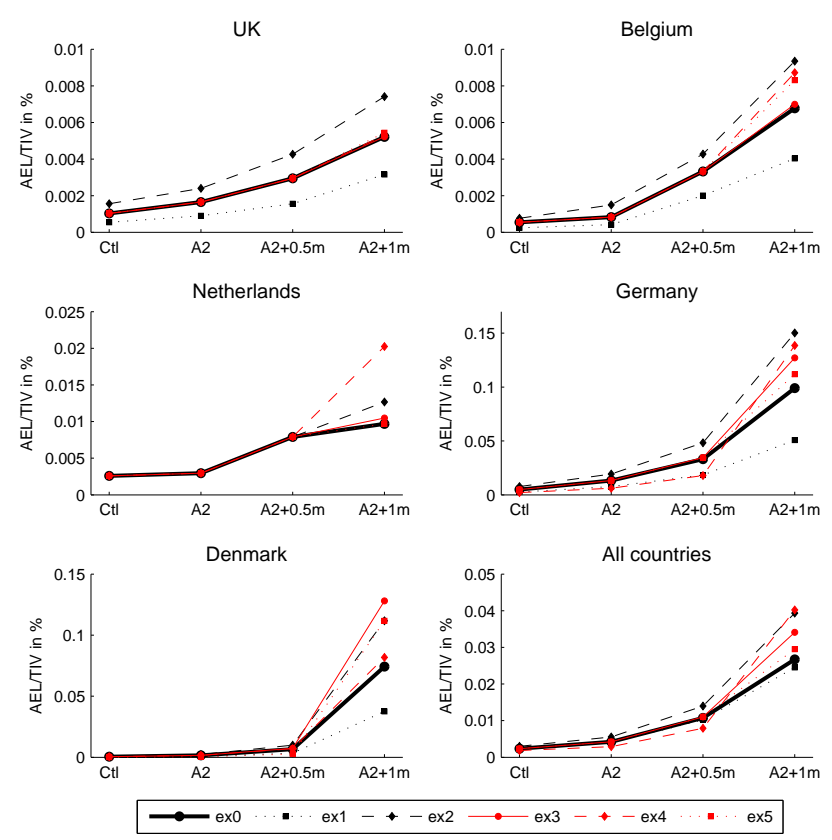

Fig. 7. Loss model sensitivity to the failure probability parameters illustrated by the AEL/TIV ratios for the Ctl and the A2 + SLR scenarios. For the experiment description see text and Table 2.

\section{Future impacts of surges on insurable losses}

Before investigating the future change in insurable loss, the model sensitivity to the dam failure parametrization is discussed as one of the sources of uncertainty. The loss model results for the analysis in this section are shown as the ratio of annual expected losses (AEL) to the total insurable value (TIV - the sum of full insurable values of property, business income values and other covered property interests) in percents.

A direct validation of the model is currently difficult to provide. There is only fragmentary information about historical insurance losses due to coastal flooding available for the North Sea region. This happened because so far, the property insurance portfolios have not covered the entire coastal area and also because coastal floods often coincide with other perils, such as wind storms, and the separation of the losses attributed to each peril is hardly manageable on a regular basis. Another obstacle is continuous change and upgrading of the coastal protection facilities, which impedes the direct comparison of present-day impact of a high water event and the impact of the same event several decades ago. For example, the February storm of 1953 would cause considerably less, if any, dam breaches and consequent damages if it happened today due to a significant improvement of the Netherlands' coastal protection since that time (Deltaworks).

The default parameter set for the loss model was chosen based on the model tests and expert judgment with respect 
Table 2. Failure probability model. SOP - standard of protection transferred from return periods to meters, CL - crest level in meters.

\begin{tabular}{lcrrrr}
\hline Load (water level) & $\begin{array}{c}\text { Failure } \\
\text { probability }\end{array}$ & $\begin{array}{c}\text { Default } p_{i} \\
\text { ex0, ex1, ex2 }\end{array}$ & \multicolumn{2}{c}{ Modified values for $p_{i}$} \\
ex3 & ex4 & ex5 \\
\hline$<0.5 \times$ SOP & $p_{1}$ & $0 \%$ & $0 \%$ & $0 \%$ & $0 \%$ \\
$>0.5 \times$ SOP, $<0.9 \times$ SOP & $p_{2}$ & $1 \%$ & $0.5 \%$ & $0.1 \%$ & $1 \%$ \\
$>0.9 \times$ SOP, $<$ SOP & $p_{3}$ & $9 \%$ & $4.5 \%$ & $0.9 \%$ & $15 \%$ \\
$>$ SOP,$<$ CL & $p_{4}$ & $90 \%$ & $95 \%$ & $99 \%$ & $84 \%$ \\
$>\mathrm{CL}$ & $p_{5}$ & $100 \%$ & $100 \%$ & $100 \%$ & $100 \%$ \\
\hline
\end{tabular}

Table 3. Failure probability model. Efficiency coefficient.

\begin{tabular}{lccccc}
\hline Country & UK & BE & NLD & GER & DNK \\
\hline$a_{\mathrm{c}}$ & 0.05 & 0.04 & 0.002 & 0.2 & 0.5
\end{tabular}

to realistic present day risks. To demonstrate the sensitivity of the results to the model setup, a number of experiments were made with different sets of failure probability parameters. Here several of them are described. The ex0 is the default parameter set $p_{1}-p_{5}, a_{\mathrm{c}}$ (Tables 2,3 ), in the experiments 1 and 2 the scaling of the failure probability curve is varied $\left(a 1_{c}=0.5 \times a_{c}, a 2_{c}=1.5 \times a_{c}\right)$. The final failure probability set $\left(a_{\mathrm{c}} \times p_{i}\right)$ differs from that for ex0, although the basic failure probabilities $\left(p_{1}-p_{5}\right)$ remain unchanged. Experiments 3-5 reflect variation in the shape of the failure probability curve and comprise both the change of basic failure probabilities (Table 2) and the corresponding change of efficiency coefficients. Five load categories remain unchanged throughout the experiments. The results for each country (separately) and the entire area as a single portfolio are shown in Fig. 7.

The main common feature which appears independent of the studied area is the annual expected loss increase for the A2 scenario with respect to the $\mathrm{Ctl}$ and a further increase when SLR is considered. In general, the changes in losses for different experiments are consistent with the parameter changes. Hence, losses from ex1 are lower and from ex2 higher than for the default setup. For all countries except the Netherlands, the changes for each scenario are almost linear and symmetric with respect to ex0. For the Netherlands the default failure probabilities are low, so only a single event from the entire event set, which corresponds roughly to $10000 \mathrm{yr}$ of data, causes the losses. A further decrease of the failure probability does not change the results for the Netherlands.

Changing the shape of failure probability curve (ex3-ex5, Table 2) tends to follow the ex0 for moderate conditions; however for the extreme A2 + $1 \mathrm{~m}$ SLR scenario the spread is
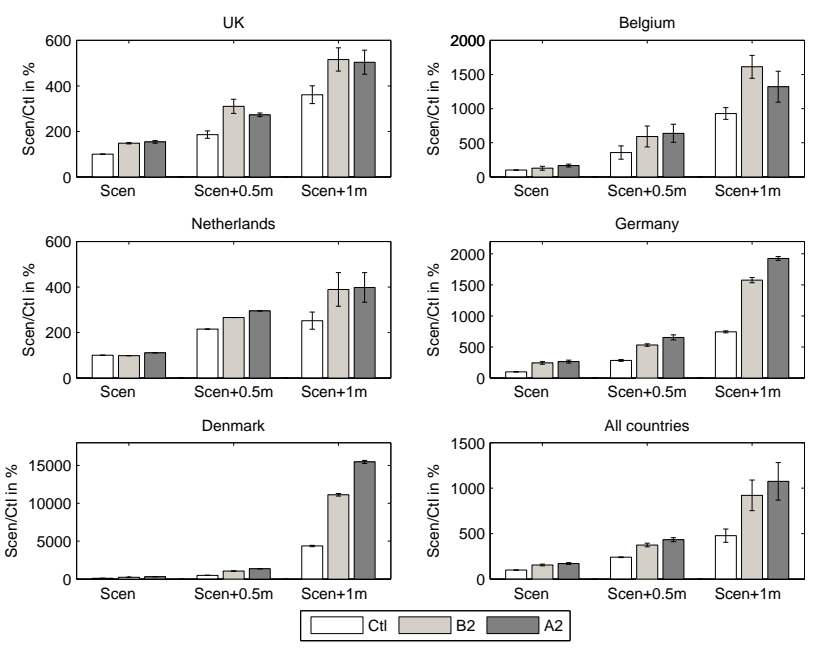

Fig. 8. Ratio of AEL for scenarios (Ctl, Ctl + SLR, A2, A2 + SLR, $\mathrm{B} 2, \mathrm{~B} 2+\mathrm{SLR}$ ) with respect to present day conditions (control) in percent. Error bars represent uncertainty due to coastal protection parameter variation.

increased. The strong response of the estimated losses to the changes in failure probabilities emerges for the water levels close to the heights of the dam SOP. Thus, coastal protection characteristics such as SOP and failure probabilities for the high water levels are crucial for accurate loss estimates.

One of the aims of this study is to estimate the rate of change for the potential future losses under the changed climate conditions with respect to present-day losses. The results are presented in the form of a ratio between future and present-day annual expected losses $(\mathrm{AEL}(\mathrm{Scen}) / \mathrm{AEL}(\mathrm{Ctl}) \times 100 \%)$. Storm surge scenarios A2 and B2 are shown alone and in combination with SLR scenarios, also the SLR effect superimposed on the present-day storm surge conditions is presented (Fig. 8).

The increase of AEL has been found for all future scenarios and all countries. The losses caused only by the altered storm surge climate vary between $115 \%$ and $330 \%$ with respect to today's losses with maxima for Germany and 
Denmark. These results are consistent with future projections for storm surge statistics, which show more pronounced increase of the future surge heights for the southeast North Sea (Fig. 5). Considering a moderate $0.5 \mathrm{~m} \mathrm{SLR}$, the losses increase. This increase becomes even more pronounced for the future (compare difference between white and grey bars in first and second groups in Fig. 8). This effect is further enhanced for $1 \mathrm{~m}$ SLR, especially for Germany and Denmark, where the future storm surge changes will be higher. This confirms the necessity to assess the socio-economic impacts of coastal floods based on the combination of SLR and storm surge projections, as the common effect is nonlinear.

The loss increase for Germany and the UK due to storm surge changes are comparable to the effect from the mean sea level raised by $0.5 \mathrm{~m}$. For other countries the storm surge impact on losses is about two times smaller than the impact of the $0.5 \mathrm{~m}$ SLR. The disproportionate loss increase for Denmark in case of $1 \mathrm{~m}$ SLR can be explained by relatively low SOP values for this country in the model, so in case of extreme SLR and surge climate water levels comparable to the dam heights occur, which leads to a significant increase in failure probability and an uneven loss increase.

The error bars in Fig. 8 represent the variance of the loss model results obtained with disturbed failure probability parameters, considering ex0-ex2. This parameter variation expresses a realistic range of errors in the model parametrization, so the error bars can serve as an indicator of the result uncertainty due to the loss model. Although the absolute AEL/TIV values were changed significantly (Fig. 7), the relative Scenario/Ctl losses show a rather small variance, in general not larger than $20 \%$ of the total values with somewhat higher values for Belgium. Another source of uncertainty for the future insurable losses appears due to different future development scenarios represented by the $\mathrm{A} 2$ and B2 scenario results. Here the uncertainty varies between $4 \%$ and $25 \%$ of total losses depending on the country and SLR case. The B2 losses are lower for most of the countries except the UK and Belgium in the extreme $1 \mathrm{~m}$ SLR case. However, the differences diminish when the model uncertainty is taken into account, so the results between scenarios are distinguishable only for Germany and Denmark. The robustness of the model to the uncertainties associated with the event set definition, in particular the estimated frequency of events, was additionally tested by reducing the estimated events frequencies. Frequencies decreased by $7 \%-9 \%$, depending on the scenario, were tested (for the source of the values see Sect. 3.1). It was found that the new ratios of future and present-day AEL behaved similarly to those obtained with the original event set for all scenarios and generally fall within the varience range shown in Fig. 8.

\section{Discussion and summary}

This study presents a tool to estimate insurance losses related to storm surges for the first time. The approach is based on coupling a dynamical storm surge model with a loss model. To show the method's ability, the climate change influence on insurable losses is assessed for the North Sea basin. Both the changes of storm surges and increased mean sea level have been taken into account.

An increase of future insurable losses with respect to the present day was found for the entire region. This is consistent with the intensification of storm surge extremes and decrease of their return periods for the future climate scenarios (Lowe and Gregory, 2005; Woth, 2005a). The increase of the losses strongly varies between the countries surrounding the North Sea, reflecting the spatial variability of the surge statistics changes as well as the specifics of national coastal protection. The loss increase due to the SLR of $0.5 \mathrm{~m}$ is comparable to the increase associated with the storm surge scenarios for Germany, Denmark and UK, whereas for Belgium and the Netherlands, the storm surge effect is negligible with respect to the effect of SLR. These dissimilar impacts on the country level are in line with the changes found for the storm surge extremes, which are more pronounced for the southeastern part of North Sea. For the combination of SLR, in particular the SLR of $1 \mathrm{~m}$, and storm surge scenarios, the altered storm surge conditions become more significant, showing the importance of considering both processes in future impact studies.

The study shows that the storm surge data obtained with a dynamical model is appropriate for this type of analysis. It provides the realistic water level distributions along the coast for particular storms, considers various storm situations and corresponding frequencies of occurrence, and reflects the alteration of storm surge statistics due to future climate change. Absolute water levels are important to assess coastal damages. The underestimation of the storm surge extremes commonly found in control simulations and inherent in currently available storm surge data sets (Flather et al., 1998; Woth, 2005b) has been solved by a calibration procedure (Raible et al., 2011).

Due to the complexity of the problem, a number of assumptions and simplifications were made which offer potential for future development of such models. For example, the storm surge data used in this study have a $10 \mathrm{~km}$ resolution, which is reasonable to represent the regional surge height distribution and correctly simulate the water levels for open sea or coastal areas with straight coast and relatively deep water. However, storm surge heights can be significantly altered in shallow water regions (e.g., tidal flats), areas with complex coastlines and topography as well as river estuaries. This would require more highly resolved simulations which would take into account the non-linear interactions between surge, SLR, tide and waves. Such high-resolution scenarios have very high computational costs and are presently realized 
only for local and short-term studies. Furthermore, water levels near the coast are subject to local SLR, which can deviate from the global mean value and be non-uniform for the basin. Local circulation and bathymetric features as well as vertical land movement of the coast contribute to the variability of the SLR. Another important factor not considered explicitly in this model is wave action. It influences primarily the dam stability, not so much the flood extent, and in the present study is implied in the failure probability parameterization.

To conclude, this study provides a first insight into the possible effects of sea level and storm surge climatology changes caused by climate change on insurable losses and underlines the importance of accurate and detailed information about coastal protection facilities and estimation of their failure probabilities. Despite the number of assumptions and simplifications, the methodology can be applied to loss-estimation problems in similar regions, providing first-order information for insurance companies as well as for climate change socio-economic impact and adaptation studies.

Acknowledgements. The authors would like to thank the HZG, in particular Ralf Weisse and Hans von Storch for making the surge model output available for our study. The digital terrain model for Europe was kindly provided by Intermap Technologies Inc. The work of this paper is supported by a joint project of SwissRe and the National Centre for Competence in Research (NCCR) in Climate funded by the Swiss National Science Foundation. We also thank Beate Gardeike for helping with some figures.

Edited by: U. Ulbrich

Reviewed by: N. Nadal and two other anonymous referees

\section{References}

Alexandersson, H., Schmith, T., Iden, K., and Tuomenvirta, H.: Longterm variations of the storm climate over NW Europe, Glob. Atmos. Ocean. Syst., 6, 97-120, 1998.

Alexandersson, H., Tuomenvirta, H., Schmith, T., and Iden, K.: Trends of stroms in NW Europe derived form an updated pressure data set, Clim. Res., 14, 71-73, 2000.

Aspelien, T. and Weisse, R.: Assimilation of Sea level Observations for multi-decadal regional ocean model simulations for the North Sea, Tech. Rep. 2, GKSS Report, 2005.

Beniston, M., Stephenson, D. B., Christensen, O. B., Ferro, C. A. T., Frei, C., Goyette, S., Halsnaes, K., Holt, T., Jylhä, K., Koffi, B., Palutikof, J., Schöll, R., Semmler, T., and Woth, K.: Future extreme events in European climate: An exploration of regional climate model projections, Clim. Change, 81, 71-95, doi:10.1007/s10584-006-9226-z, 2007.

Bindoff, N., Willebrand, J., Artale, V., Cazenave, A., Gregory, J., Gulev, S., Hanawa, K., Quéré, C. L., Levitus, S., Nojiri, Y., Shum, C., Talley, L. D., and Unnikrishnan, A.: Observations: Oceanic Climate Change and Sea Level, in: Climate Change 2007: The Physical Science Basis, Contribution of Working Group I to the Fourth Assessment Report of the Intergovernmental Panel on Climate Change, Cambridge University Press, Cambridge, United Kingdom and New York, NY, USA, 2007.
Casulli, V. and Cattani, E.: Stability, accuracy and efficiency of a semi-implicit method for three dimensional shallow water flow, Computers Math. Applic., 27, 99-112, 1994.

Christensen, J., Carter, T., and Giorgi, F.: PRUDENCE employs new methods to assess European climate change, EOS, Transactions, American Geophysical Union, 83, p. 147, 2002.

Dawson, R. and Hall, J.: Adaptive importance sampling for risk analysis of complex infrastructure systems, Proc. R. Soc. A, 462, 3343-3362, 2006.

Debernard, J. and Røed, L.: Future wind, wave and storm surge climate in the Northern Seas: a revisit, Tellus Ser. A, 60, 427438, doi:10.1111/j.1600-0870.2008.00312.x, 2008.

Deltaworks: http://www.deltawerken.com (last access: November 2010), 2010.

Döscher, R., Willén, U., Jones, C., Rutgersson, A., Meier, H., Hansson, U., and Graham, L.: The development of the coupled regional ocean-atmosphere model RCAO, Boreal Env. Res., 7, 183-192, 2002.

Eurostat. Unit E1, Farms, Agro-environment and rural development: Statistics in focus, Agriculture and fisheries, Tech. rep., Eurostat. European commission, 47, 1-12, 2009.

Feser, F., Weisse, R., and von Storch, H.: Multi-decadal atmospheric modeling for Europe yields multi-purpose data, EOS Transactions, 82, 305-310, 2001.

Flather, R., Smith, J., Richards, J., Bell, C., and Blackman, D.: Direct estimates of extreme surge elevation from a 40 year numerical model simulation and from observations, Global Atmos. Ocean Sys., 6, 165-176, 1998.

Floris project: Flood risks and safety in the Netherlands (Floris), Floris study - Full report, Tech. rep., Ministry of Transport, Public Works and Water Management, The Netherlands, 54-65, 2005.

Gönnert, G., Dube, S., Murty, T., and Siefert, W.: Global storm surges, Die Küste, 63, 375 pp., 2001.

Gumbel, E.: The statistics of extremes, Columbia University Press, New York, 510 pp., 1958.

Hall, J., Dawson, R., Sayers, P., Rosu, C., Chatterton, J., and Deakin, R.: A methodology for national-scale flood risk assessment, Proceedings of the Institution of Civil Engineers, WM3, 235-247, 2003.

Hervouet, J. and Haren, L.: TELEMAC2D Version 3.0 Principle Note Rapport EDF HE-4394052B, Tech. rep., Electricité de France, Département Laboratoire National de Hydraulique, Chatou CEDEX, 1996.

Jorissen, R., Litjens, J., and Lorenzo, A.: Flooding risk in coastal areas, Risks, safety levels and probabilistic techniques in five countries along the North Sea coast, Tech. rep., The Hague, Ministry of Transport, Public Works and Water Management, 61 pp., 2000.

Kistler, R., Kalnay, E., Collins, W., Saha, S., White, G., Wollen, J., Chelliah, M., Ebisuzaki, W., Kanamitsu, M., Kousky, V., van den Dool, H., Jenne, R., and Fioriono, M.: The NCEP/NCAR 50year reanalysis: monthly means CD-ROM and documentation, Bull. Amer. Meteorol. Soc., 82, 247-267, 2001.

Loffredo, L., Schulz, D., and Wilkens, J.: Design parameters for coastal dikes, Case study: Meldorf on the German North Sea, Environ. Fluid. Mech., 7, 469-479, 2007.

Lowe, J. and Gregory, J.: The effects of climate change on storm surges around the United Kingdom, Phil. Trans. R. Soc. A, 363, 
1313-1328, doi:10.1098/rsta.2005.1570, 2005.

Lowe, J., Gregory, J., and Flather, R.: Changes in the occurrence of storm surges around the United Kingdom under a future climate scenario using a dynamic storm surge model driven by Hadley Centre climate models, Clim. Dyn., 18, 179-188, 2001.

Matulla, C., Schöner, W., Alexandersson, H., von Storchad, X. L., and Wang, H.: European storminess: Late nineteenth century to present, Clim. Dyn., 31, 125-130, doi:10.1007/s00382-0070333-y, 2008.

Nicholls, R.: Coastal flooding and wetland loss in the 21st century: Changes under the SRES climate and socio-economic scenarios, Glob. Environ. Change, 14, 69-86, 2004.

Raible, C. C., Della-Marta, P., Schwierz, C., Wernli, H., and Blender, R.: Northern Hemisphere Extratropical Cyclones: A Comparison of Detection and Tracking Methods and Different Reanalyses, Mon. Weather Rev., 136, 880-897, 2008.

Raible, C. C., Kleppek, S., Wueest, M., Kitoh, A., Murakami, H., Stocker, T. F., and Bresch, D. N.: Atlantic Hurricanes and Associated Insurance Loss Potentials in Future Climate Scenarios, Tellus A, submitted, 2011.

Rockel, B. and Woth, K.: Future changes in near surface wind speed extremes over Europe from an ensemble of RCM simulations, Clim. Change, 81, 267-280, doi:10.1007/s10584-0069227-y, 2007.

Roeckner, E., Bengtsson, L., Feichter, J., Lelieveld, J., and Rodhe, H.: Transient climate change simulations with a coupled atmosphere-ocean GCM including the tropospheric sulphur cycle, J. Clim., 12, 3004-3032, 1999.
Schwierz, C., Köllner-Heck, P., Zenklusen, E., Bresch, D., Vidale, P.-L., Wild, M., and Schär, C.: Modelling European winter wind storm losses in current and future climate, Clim. Change, 101, 485-514, doi:10.1007/s10584-009-9712-1, 2010.

Swiss Re: Natural catastrophes and reinsurance, Tech. rep., Swiss Reinsurance Company Publications, Zürich, 47 pp., 2003.

Ulbrich, U., Leckebusch, G. C., and Pinto, J. G.: Extra-tropical cyclones in the present and future climate: a review, Theor. Appl. Climatol., 96, 117-131, 2009.

Weisse, R. and Pluess, A.: Storm-related sea level variations along the North Sea coast as simulated by a high-resolution model 1958-2002, Ocean Dyn., 56, 16-25, 2006.

Weisse, R., von Storch, H., and Feser, F.: Northeast Atlantic and North Sea storminess as simulated by a regional climate model during 1958-2001 and comparison with observations, J. Climate, 18(3), 465-479, 2005.

Woth, K.: Projections of North Sea storm surge extremes in a warmer climate: How important are the RCM driving GCM and the chosen emission scenario?, Geophys. Res. Lett., 32, 122708, doi:10.1029/2005GL023762, 2005a.

Woth, K.: Regionalization of global climate change scenarios: An ensemble study of possible changes in the North Sea storm surge statistics, Ph.D. thesis, Fachbereich Geowissenschaften der Universität Hamburg, 2005b.

Woth, K., Weisse, R., and von Storch, H.: Climate change and North Sea storm surge extremes: An ensemble study of storm surge extremes expected in a changed climate projected by four different regional climate models, Ocean Dyn., 56, 3-15, 2006. 